\title{
Selective Alterations in Postsynaptic Markers of Chandelier Cell Inputs to Cortical Pyramidal Neurons in Subjects with Schizophrenia
}

\author{
Dianne A Cruz ${ }^{1,4}$, Cassandra L Weaver', Emily M Lovallo², Darlene S Melchitzky ${ }^{1,3}$ and David A Lewis*,1,2 \\ 'Department of Psychiatry, University of Pittsburgh, Pittsburgh, PA, USA; ${ }^{2}$ Neuroscience, University of Pittsburgh, Pittsburgh, PA, USA; \\ ${ }^{3}$ Department of Biology, Mercyhurst College, Erie, PA, USA
}

\begin{abstract}
Markers of GABA neurotransmission between chandelier neurons and their synaptic targets, the axon initial segment (AIS) of pyramidal neurons, are altered in the dorsolateral prefrontal cortex (dIPFC) of subjects with schizophrenia. For example, immunoreactivity for the GABA membrane transporter (GATI) is decreased in presynaptic chandelier neuron axon terminals, whereas immunoreactivity for the $\mathrm{GABA}_{A}$ receptor $\alpha 2$ subunit is increased in postsynaptic AIS. To understand the nature and functional significance of these alterations, we determined the density, laminar distribution, and length of AIS immunoreactive (IR) for ankryin-G and $\beta$ IV spectrin, two proteins involved in the regulation of synapse structure and ion channel clustering at AIS, in dIPFC area 46 from 14 matched triads of subjects with schizophrenia or major depressive disorder (MDD) and normal comparison participants. The density of ankyrin-G-IR AIS in the superficial, but not in the deep, cortical layers was significantly decreased by 15-19\% in the subjects with schizophrenia relative to the other participant groups. In contrast, no group differences were present in the density of $\beta \mathrm{IV}$ spectrin-IR AIS. The length of labeled AIS did not differ across participant groups for either ankyrin-G or $\beta I V$ spectrin. The density of ankyrin-G-IR AIS was not altered in the dIPFC of macaque monkeys chronically exposed to antipsychotic medications. Given the important role of ankyrin-G in the recruitment and stabilization of sodium channels and other integral membrane proteins to AIS, our findings suggest that these processes are selectively altered in superficial layer pyramidal neurons in subjects with schizophrenia.
\end{abstract}

Neuropsychopharmacology (2009) 34, 2 II2-2124; doi: I0.1038/npp.2009.36; published online 25 March 2009

Keywords: ankyrin-G; $\beta I V$ spectrin; axon initial segment; GABA; prefrontal cortex

\section{INTRODUCTION}

Postmortem studies have revealed alterations in both preand post-synaptic markers of GABA neurotransmission in the dorsolateral prefrontal cortex (dlPFC) of subjects with schizophrenia. Presynaptically, levels of the mRNAs encoding (1) the $67-\mathrm{kDa}$ isoform of glutamic acid decarboxylase $\left(G_{A D}\right)$, the principal enzyme responsible for the synthesis of GABA; (2) the GABA membrane transporter (GAT1); and (3) the calcium-binding protein parvalbumin (PV) are lower in schizophrenia (Volk et al, 2000; Volk et al, 2001; Hashimoto et al, 2003; Akbarian et al, 1995; Ohnuma et al, 1999; Guidotti et al, 2000; Hashimoto et al, 2008). These alterations are accompanied by reduced GAT1 immuno-

*Correspondence: Dr DA Lewis, Department of Psychiatry, University of Pittsburgh, 381 I O'Hara Street, W I65 I BST, Pittsburgh, PA I52 I3, USA, Tel: + 1412624 3934, Fax: + 14126249910 ,

E-mail: lewisda@upmc.edu

${ }^{4}$ Current address: Department of Psychiatry, University of Texas Health Science Center at San Antonio

Received 18 December 2008; revised II February 2009; accepted 12 February 2009 reactivity in the characteristic axon terminals (termed cartridges) of PV-containing chandelier neurons (Woo et al, 1998; Pierri et al, 1999) that form symmetric synapses onto the axon initial segments (AISs) of pyramidal neurons in the primate dlPFC (Williams et al, 1992; Melchitzky et al, 1999). Postsynaptically, immunoreactivity for the $\mathrm{GABA}_{\mathrm{A}}$ receptor $\alpha_{2}$ subunit is increased in pyramidal neuron AIS in the dlPFC of subjects with schizophrenia (Volk et al, 2002). Together, these findings suggest that deficient GABA synthesis in chandelier neurons in schizophrenia, with the changes in GAT1, PV, and $\mathrm{GABA}_{\mathrm{A}}$ receptors reflecting compensatory responses to augment the efficacy of GABA inputs to pyramidal neuron AIS (Lewis et al, 2005).

However, understanding the nature and functional significance of these alterations requires knowledge of other processes that affect GABA neurotransmission at pyramidal neuron AIS in schizophrenia. Of particular interest is whether the alterations in pre- and post-synaptic markers of GABA neurotransmission are accompanied by changes in proteins that regulate synapse structure and ion channel clustering in pyramidal neuron AIS. For example, the 480and $270-\mathrm{kDa}$ isoforms of ankyrin-G, members of a class of 
adaptor molecules that link various membrane proteins to the cytoskeleton, are localized to AIS (and nodes of Ranvier) of certain neurons, including cortical pyramidal neurons (Kordeli et al, 1995; Susuki and Rasband, 2008). In the cerebellum, ankyrin-G interacts with the neuronal cell adhesion molecule neurofascin to recruit and stabilize GABA synapses at the AIS of Purkinje cells (Ango et al, 2004). Binding to ankyrin $G$ is also essential for the localization of many other membrane proteins to the AIS (Susuki and Rasband, 2008), including the voltage-gated $\mathrm{Na}^{+}$ channels that are required for action potential generation (Zhou et al, 1998). In addition, the cytoskeletal protein $\beta \mathrm{IV}$ spectrin, which is localized to the AIS of pyramidal neurons through its direct interaction with ankryin-G (Yang et al 2007), is a critical component in the maintenance of membrane structure and molecular organization (LacasGervais et al, 2004), and thus the stability (Yang et al, 2007) of AIS.

Given the importance of these proteins in pyramidal neuron AIS structure and function, we examined human postmortem brain tissue containing dlPFC area 46 to determine whether the laminar densities of AIS immunoreactive (IR) for ankyrin-G or $\beta \mathrm{IV}$ spectrin are altered in subjects with schizophrenia relative to normal control participants and subjects with major depressive disorder (MDD). We also determined (1) the impact of potential clinical confounds on these measures, (2) the length of ankyrin-G- and $\beta$ IV spectrin-IR AIS in the same participants, and (3) the density of labeled AIS in area 46 of macaque monkeys chronically exposed to typical or atypical antipsychotic medications.

\section{METHODS}

\section{Characteristics of Study Participants}

Brain tissue from 42 participants was collected during autopsies conducted at the Allegheny County Medical Examiner's Office after consent was obtained from the next-of-kin (Table 1). All procedures were approved by the University of Pittsburgh's Committee for Oversight of Research Involving the Dead and Institutional Review Board for Biomedical Research. Consensus DMS-IV diagnoses were made by an independent panel of experienced clinicians using information obtained from structured interviews with relatives and review of medical records (Glantz and Lewis, 1997). Each subject with schizophrenia was matched to one normal comparison participant and one subject with MDD on the basis of sex, and as closely as possible for age and postmortem interval (PMI), creating 14 participant triads for the purposes of tissue processing. The mean $( \pm S D)$ age (comparison: $52.4 \pm 8.6$ years; schizophrenia: $52.6 \pm 8.5$ years; MDD: $53.0 \pm 7.6$ years; $\mathrm{F}_{2,39}=0.02$, $p=0.98$ ) and PMI (comparison: $11.8 \pm 5.9 \mathrm{~h}$; schizophrenia: $13.4 \pm 5.8 \mathrm{~h}$; MDD: $\left.13.5 \pm 5.7 \mathrm{~h} ; \mathrm{F}_{2,39}=0.38, p=0.69\right)$ did not differ across participant groups. The mean age of illness onset was $29.9 \pm 9.4$ years for the schizophrenia participants and $41.6 \pm 10.7$ years for the MDD participants. Neuropathological evaluations revealed no abnormalities in any participants. This same cohort of participants has been used in earlier studies of markers of chandelier neuron axon terminals and pyramidal neuron AIS (Pierri et al, 1999; Volk et al, 2002).

\section{Tissue Processing}

The left hemisphere of the brain was cut into standardized coronal blocks $(\sim 1.2 \mathrm{~cm}$ thick $)$. Tissue blocks were immersed in $4 \%$ paraformaldehyde in phosphate buffer for $48 \mathrm{~h}$ and stored in a cryoprotectant solution at $-30^{\circ} \mathrm{C}$ (Cruz et al, 2003). Earlier studies have shown that storage under these conditions does not affect immunoreactivity for a number of proteins (Erickson et al, 1998; Pierri et al, 1999; Cruz et al, 2003). Mean tissue storage times (eg for the ankyrin-G immunocytochemical study, normal comparison: $135 \pm 29$ months; schizophrenia: $141 \pm 28$ months; MDD: $121 \pm 34$ months $)$ did not differ $\left(\mathrm{F}_{2,39}=1.65 ; p=0.206\right)$ across participant groups. Tissue blocks were sectioned $(40 \mu \mathrm{m})$ coronally on a cryostat and a sample of equally spaced sections through the entire block were stained for Nissl substance with thionin. The stained sections were used to identify area 46 (Figure 1a) of the dlPFC according to cytoarchitectonic criteria (Daviss and Lewis, 1995; Rajkowska and Goldman-Rakic, 1995).

Three sets of adjacent tissue sections approximately $400 \mu \mathrm{m}$ apart and each containing dlPFC area 46 from each participants were processed in a randomized block design (ie with one section from each participant in a triad always processed together and with different combinations of triads in each immunocytochemical experiment). One set of sections was processed for ankyrin-G immunoreactivity with a mouse monoclonal $\operatorname{IgG}_{1}$ antibody (1:200 dilution, Santa Cruz Biotechnology, Santa Cruz, CA) that recognizes the 480 and $270 \mathrm{kDa}$ isoforms of the protein; the adjacent set of sections was processed for $\beta$ IV spectrin immunoreactivity with a rabbit polyclonal antibody (1:750 dilution, kindly provided by Dr Matthew Rasband, Baylor College of Medicine, Houston, TX) raised against the specific domain (SD) of $\beta$ IV spectrin. Exclusion of the primary antibodies in control experiments resulted in the complete absence of immunoreactivity (data not shown). The specificity of these antibodies has been shown by the absence of immunoreactivity in tissue from mice with genetic deletions of ankyrin-G (Jenkins et al, 2001; Jenkins and Bennett, 2001; Zhou et al, 1998) or $\beta \mathrm{IV}$ spectrin-SD (Yang et al, 2004).

To ensure adequate visualization of the proteins of interest, tissue sections were treated with an antigen retrieval procedure (Jiao et al, 1999) before primary antibody incubation. Tissue sections were placed in a $0.01-\mathrm{M}$ sodium citrate solution $(\mathrm{pH} 8.5)$ at $80^{\circ} \mathrm{C}$ for $75 \mathrm{~min}$, then by $30 \mathrm{~min}$ in $1 \% \mathrm{NaBH}_{4}$ as described earlier (Cruz et al 2003). Sections were then (1) incubated in one of the primary antibodies for $48 \mathrm{~h}$ at $4{ }^{\circ} \mathrm{C}$, (2) incubated in a biotinylated donkey anti-mouse (ankyrin-G) or a biotinylated donkey anti-rabbit ( $\beta$ IV spectrin) secondary antibody ( $1: 200$ dilution, Vector Laboratories, Burlingame, CA) for $1 \mathrm{~h}$ at room temperature, (3) processed with a Vectastain $\mathrm{ABC}$ kit (Vector Laboratories) and diaminobenzidine, and (4) mounted on coded slides. The diaminobenzidine reaction product was stabilized by osmium tetroxide (Lewis et al, 1986) and intensified with silver nitrate and gold chloride (Pucak et al, 1996). 
Table I Subject Characteristics

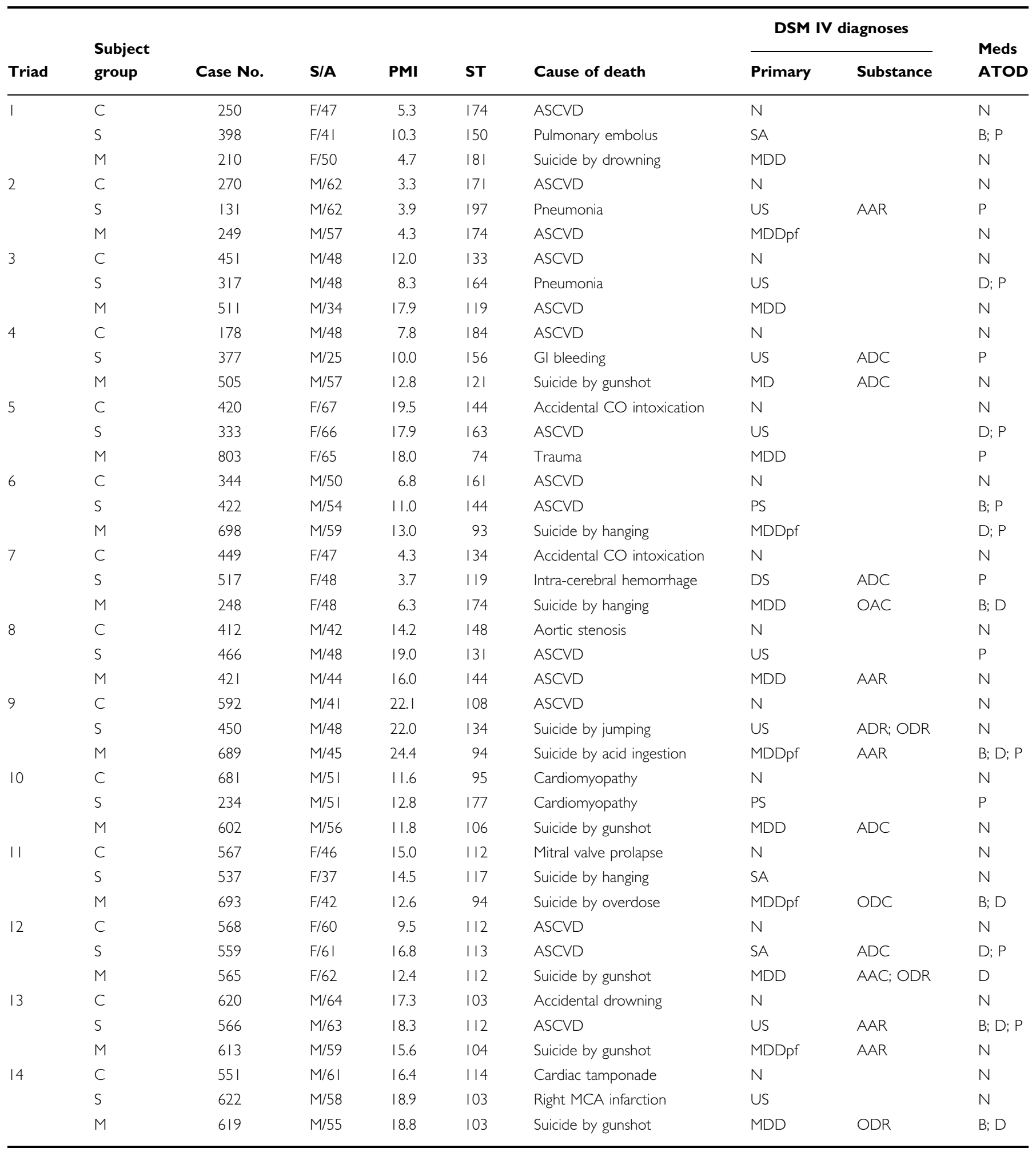

C, normal comparison; S, schizophrenia; M, mood disorder; A, age in years; F, female; $\mathrm{M}$, male; $\mathrm{S}$, sex; PMI, postmortem interval; ST, storage time in months at -80 ${ }^{\circ} \mathrm{C}$; ASCVD, atherosclerotic cardiovascular disease; CO, carbon monoxide; COPD, chronic obstructive pulmonary disease; OD, overdose; pf, psychotic features; DS, disorganized schizophrenia; PS, paranoid schizophrenia; SA, schizoaffective disorder; US, undifferentiated schizophrenia; AAC, alcohol abuse, current at time of death; $A A R$, alcohol abuse, in remission at time of death; ADC, alcohol dependence, current at time of death; ADR, alcohol dependence, in remission at time of death; MD$\mathrm{M}$, mood disorder due to a general medical condition; MDD, major depressive disorder; ODC, other substance dependence, current at time of death; ODR, other substance dependence, in remission at time of death; OAC, other substance abuse, current at time of death; OAR, other substance abuse, in remission at time of death; Meds ATOD, medications at time of death; B, benzodiazepines; D, antidepressants; N, none; P, antipsychotics. 

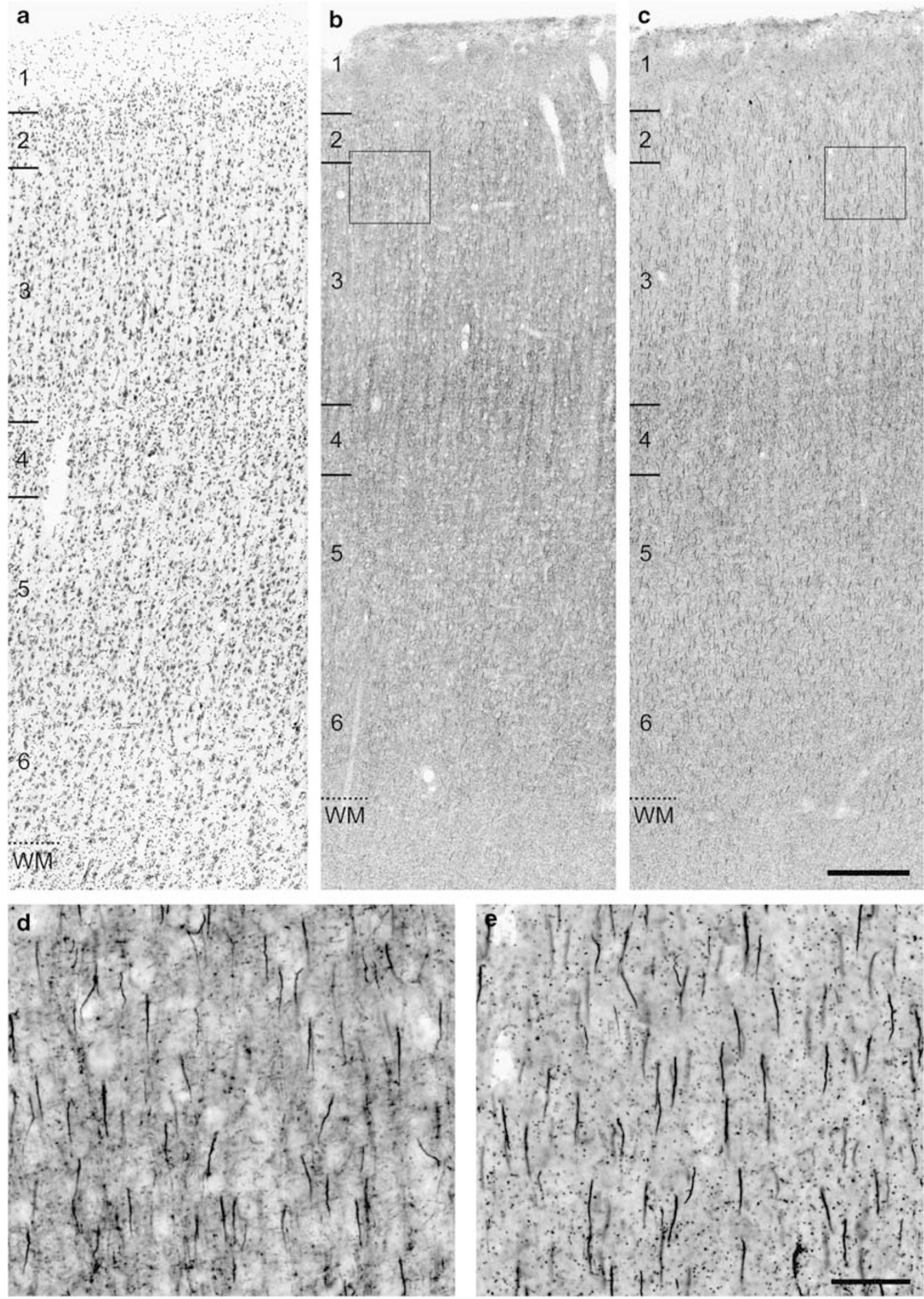

Figure I Brightfield photomicrographs of a Nissl-stained section (a) showing the normal cytoarchitecture of human dIPFC area 46 and of adjacent sections labeled for ankyrin-G (b) and $\beta \mathrm{IV}$ spectrin-SD (c) immunoreactivity. Numerals indicate cortical layers, and the dashed line represents the layer 6 - white matter (WM) border. Boxes in (b) and (c) approximate the location of higher power photomicrographs in (d) and (e), which show the AIS of pyramidal neurons immunoreactive for ankyrin G (d) and $\beta \mathrm{IV}$ spectrin-SD (e), as well as punctate labeling for each marker that likely represents nodes of Ranvier. Scale bars $=300 \mu \mathrm{m}(\mathrm{a}-\mathrm{c}) ; 50 \mu \mathrm{m}(\mathrm{d}, \mathrm{e})$

\section{Quantification}

The densities (number per $\mathrm{mm}^{2}$ ) of pyramidal neuron AIS labeled with each antibody were quantified using the Stereo Investigator fractionator software (MicroBrightfield, Inc.,
Colchester, VT). For each section, the portion of area 46 cut perpendicular to the pial surface was identified, and two cortical zones were delineated as follows: $25 \%$ of the cortical depth immediately below the border of layers 1-2 (which corresponds to layers 2 and superficial 3) was defined as the 
superficial zone, and $20 \%$ of the cortical depth immediately above the layer 6-white matter border (which corresponds to layer 6) was defined as the deep zone. These cortical zones were chosen to follow the procedures used in earlier studies of pre- and post-synaptic markers of GABA neurotransmission in the same participants (Pierri et al, 1999; Volk et al, 2002). Using a $5 \times$ objective (final on screen magnification of $(20 \times)$, a contour was drawn around each cortical zone and a sampling grid $300 \times 300 \mu \mathrm{m}$ (superficial) or $200 \times 200 \mu \mathrm{m}$ (deep) was placed in a random orientation over the contour. A counting frame $(60 \times$ $60 \mu \mathrm{m}$ ) within each grid square was defined as the region of quantification. For quantification of AIS IR for ankyrin-G, the mean $( \pm S D)$ numbers of counting frames per section for the superficial and deep zones were 35.4 (12.3) and 60.1 (15.9), respectively. The mean ( $\pm S D$ ) numbers of counting frames per section for $\beta$ IV spectrin IR AIS in the superficial and deep zones were 37.2 (10.1) and 65.3 (19.2), respectively. As described earlier, AISs were identified as intensely IR processes perpendicular to the pial surface that tapered slightly in the direction from pia to white matter (Volk et al 2002). With a $40 \times$ objective (final on screen magnification of $960 \times$ ), all IR AIS in the inclusion boundaries of the counting frames were identified.

One rater quantified all ankyrin-G-IR AIS (D.A.C.) and a second rater (C.L.W.) quantified all $\beta$ IV spectrin-SD-IR AIS. Both raters were blind to the participant number and diagnosis of each section. Intra-rater reliability was confirmed by intra-class correlation coefficients (ICCs) of $0.996(95 \% \mathrm{CI}=0.971-0.998)$ for ankyrin-G and 0.986 $(95 \% \mathrm{CI}=0.952-0.996)$ for $\beta \mathrm{IV}$ spectrin-SD. Inter-rater reliability between D.A.C. and C.L.W. for each type of labeled AIS was confirmed with an ICC of $0.992(95 \%$ $\mathrm{CI}=0.971-0.980$ ).

The lengths of ankyrin-G- and $\beta$ IV spectrin-SD-IR AISs were analyzed with the Neurolucida software (MicroBrightfield, Inc.) using a $100 \times$, NA1.4, oil immersion objective. One section from each of the normal comparison subjects and subjects with schizophrenia was used for AIS length analysis. For both ankyrin-G and $\beta$ IV spectrin-SD, 20 IR AISs in the superficial cortical zone were randomly selected, traced on a video monitor at a final magnification of $2400 \times$, and the length of the labeled AIS was determined.

\section{Effects of Antipsychotic Medications}

To assess the potential influence of antipsychotic medications on the density of ankyrin-G-IR AIS, we studied 18 male macaque monkeys (Macaca fascicularis) that had been chronically exposed to haloperidol, olanzapine, or placebo as described earlier (Dorph-Petersen et al, 2005). All procedures were approved by the University of Pittsburgh's Institutional Animal Care and Use Committee. After approximately 2 years of treatment, monkeys were euthanized in triads (composed of one animal from each treatment group), the brain was removed and tissue blocks containing the dlPFC were placed into cold $4 \%$ paraformaldehyde for $48 \mathrm{~h}$ and stored in cryoprotectant at $-30^{\circ} \mathrm{C}$. Two tissue sections $(40 \mu \mathrm{m})$ per participant containing area 46 were processed for immunocytochemistry, and the densities of ankyrin-G-IR AISs were determined, using the same procedures described earlier for the human participants. One rater quantified all the ankyrin-G-IR AIS (E.M.L.). The slides were coded so that the rater was blind to the participant number and treatment of each specimen. The intra-rater reliability of AIS counts was confirmed by ICCs of 0.993 (95\% CI $=0.946-0.999)$. The inter-rater reliability (with D.A.C.) of AIS counts resulted in an ICC of $0.983(95 \% \mathrm{CI}=0.941-0.995)$.

\section{Statistical Analyses}

The density of labeled AIS per participant was calculated as the average density of the three tissue sections. Two statistical models were used to test for effect of diagnosis in each cortical zone. In the first approach (Model 1), analyses of variance were performed with mean density of labeled AIS as the dependent variable, diagnostic group as the main effect, and participant triad as a blocking factor. As triads were used primarily to reduce experimental variance across groups and did not fully control potential differences in age, PMI, or tissue storage time, we also used ANCOVA to test for a main effect of diagnosis, including sex, age, PMI, and tissue storage time as covariates (Model 2 ). Age and tissue storage time were not significant in any of the initial analyses, so these covariates were omitted from the final analyses. The results of both statistical models are reported. The least significant difference post hoc test was used to assess the differences between diagnostic groups based on the Model 1 results.

The effect of sex, use of antipsychotic drugs, antidepressant drugs, or benzodiazepines at the time of death, history of alcohol and/or substance use disorder, and cause of death on the difference in AIS-IR density between matched schizophrenia-normal comparison participant pairs and MDD-normal comparison participant pairs were analyzed with ANCOVAs using sex and PMI as covariates. To determine whether the densities of ankyrin-G-IR AIS and $\beta$ IV spectrin-SD-IR AISs were correlated within participants, a one-tailed Pearson correlation was conducted for each diagnostic category. Differences in AIS lengths between schizophrenia and normal comparison participants were assessed with ANCOVAs using sex, age, and PMI as covariates. The differences in the mean density of ankyrinG-IR AIS across the groups of haloperidol-, olanzapine-, and placebo-exposed monkeys were assessed by ANCOVA, with experimental group as the main effect and participant triad as a covariate.

\section{Photography}

Photomicrographs (Figures 1 and 2) were generated using a Zeiss Axiocam camera. Photomontages were assembled and the brightness and contrast were adjusted in Adobe Photoshop.

\section{RESULTS}

\section{General Observations}

In area 46 of human dlPFC, immunoreactivity for both ankyrin-G and $\beta \mathrm{IV}$ spectrin-SD was most prominently localized to the AIS of pyramidal neurons in layers 2-6 

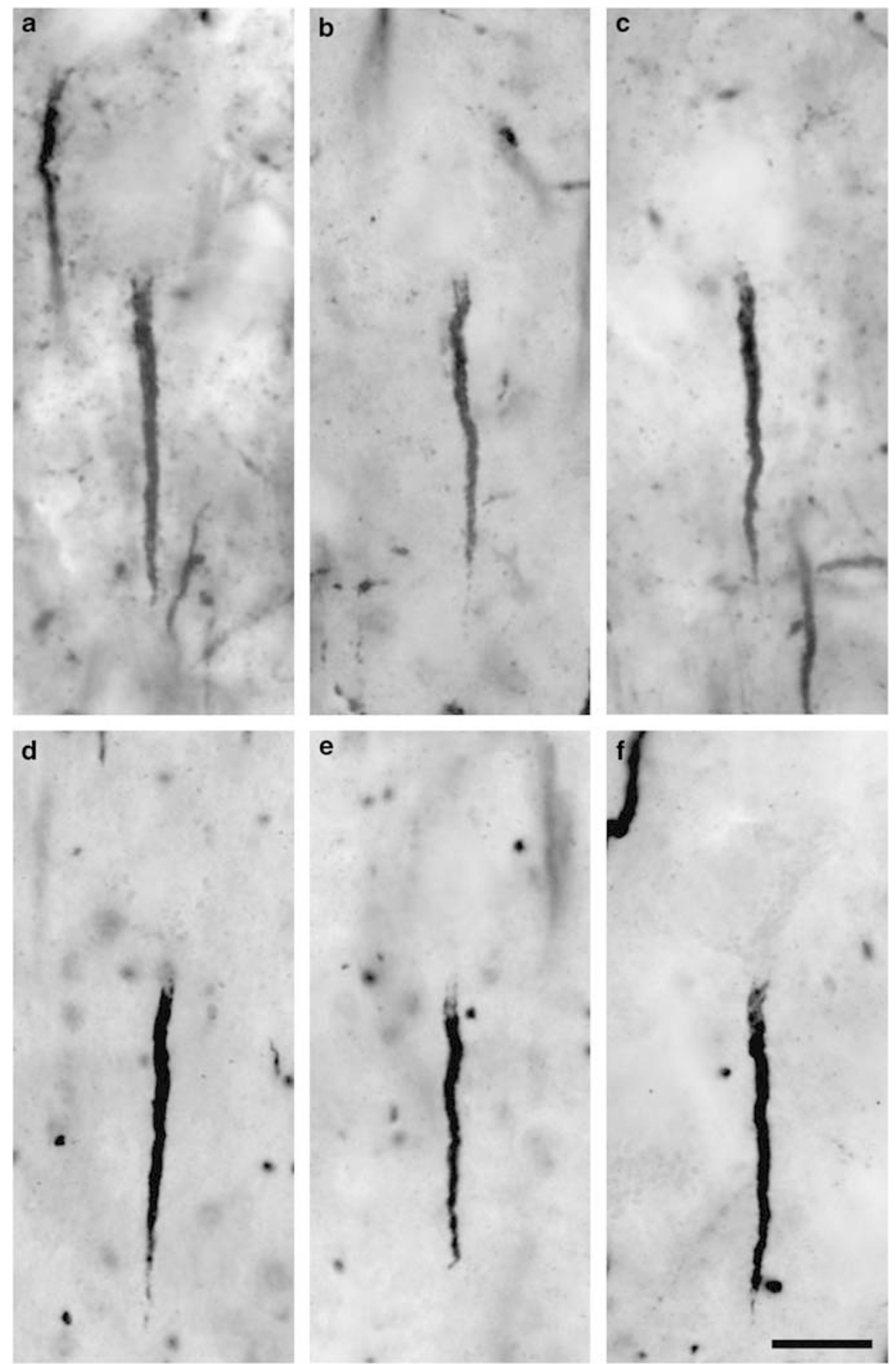

Figure 2 Brightfield photomicrographs of representative pyramidal neuron AIS in the superficial zone of dIPFC area 46 immunoreactive for ankyrin-G $(a-c)$ or $\beta I V$ spectrin-SD $(d-f)$ in control subjects $(a, d)$, schizophrenia subjects (b, e), and MDD subjects (c, f). Scale bar $=10 \mu \mathrm{m}(a-f)$.

(Figure 1). Ankyrin-G- and $\beta$ IV spectrin-SD-IR AISs were intensely IR, vertically oriented structures that were widest just beneath the base of unlabeled pyramidal neuron cell bodies and then became thinner with increasing distance from the cell body (Figure 2). In all cortical layers and the subjacent white matter, ankyrin-G and $\beta$ IV spectrin-SD immunoreactivity was also found in small punctate structures (Figure 1), which most likely represent the nodes of Ranvier of myelinated axons (Jenkins and Bennett, 2002; Zhou et al, 1998).

\section{Densities of Ankyrin-G and $\beta$ IV Spectrin-SD-IR AIS}

In the superficial cortical zone (Figure 3a), the mean $( \pm S D$ ) density of ankyrin-G-IR AIS was significantly (Model 1: $\mathrm{F}_{2,26}=5.97 ; p=0.007 ; \quad$ Model $\left.2: \mathrm{F}_{2,37}=3.63 ; p=0.036\right)$ decreased in subjects with schizophrenia $(808.0 \pm 224.4)$ by $19 \%$ relative to matched normal comparison participants (1008.8 \pm 213.8$)$ and by $15 \%$ relative to subjects with MDD (951.6 \pm 268.2$)$. Post hoc analysis revealed that mean ankyrin-G-IR AIS density in subjects with schizophrenia 


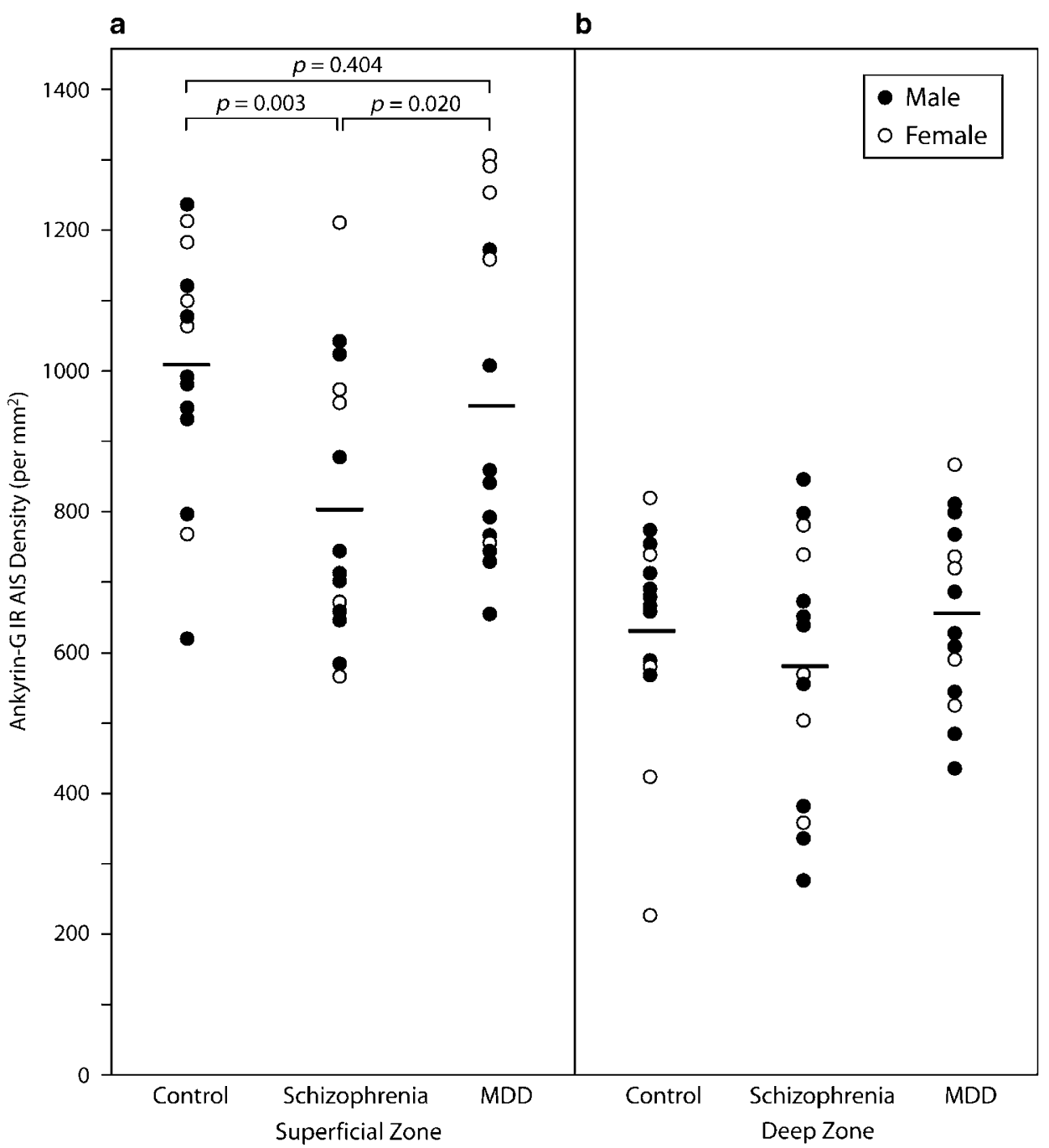

Figure 3 Scatter plots showing the mean densities of ankyrin-G immunoreactive AIS in each participant for each cortical zone. Horizontal lines indicate the mean density for each group. Note the generally higher density of ankyrin-G-labeled AIS for female participants in the superficial zone.

was significantly lower than in both normal comparison subjects $(p=0.003)$ and subjects with $\operatorname{MDD}(p=0.02)$; in contrast, the normal comparison and MDD groups did not differ $(p=0.404)$. In addition, across participant groups, the densities of ankyrin-G-IR AISs were significantly $\left(\mathrm{F}_{1,37}=5.72 ; p=0.022\right)$ greater in females than in males. In the deep cortical zone (Figure $3 b$ ), the mean densities of ankyrin-G-IR AISs were lower than in the superficial zone for each participant group but did not differ (Model 1: $\mathrm{F}_{2,26}=1.18 ; \quad p=0.322 ;$ Model $2: \mathrm{F}_{2,37}=0.91 ; p=0.411$ ) across the participant groups. No differences were observed between males and females in the deep cortical zone $\left(\mathrm{F}_{1,37}=0.05 ; p=0.826\right)$.

The mean density of $\beta \mathrm{IV}$ spectrin-SD-IR AIS (Figure 4) did not differ across participant groups in either the superficial (Model 1: $\mathrm{F}_{2,26}=1.68 ; p=0.206 ;$ Model 2: $\mathrm{F}_{2,37}=1.06 ; p=0.356$ ) or deep (Model 1: $\mathrm{F}_{2,26}=0.49$; $p=0.621$; Model $\left.2: \mathrm{F}_{2,37}=0.84 ; p=0.438\right)$ cortical zones. In addition, like ankyrin-G-IR AIS, the densities of $\beta$ IV spectrin-SD-IR AISs were significantly greater in females than in males across participant groups in the superficial zone $\left(\mathrm{F}_{1,37}=8.55 ; p=0.006\right)$ but not in the deep zone $\left(\mathrm{F}_{1,37}=1.41 ; p=0.242\right)$.
The densities of ankyrin-G- and $\beta$ IV spectrin-SD-IR AIS in the superficial zone were positively correlated in each participant group (normal comparison: $r=0.70, p=0.005$; MDD: $\quad r=0.64, \quad p=0.014$; schizophrenia: $r=0.52$, $p=0.059)$, although the density of $\beta$ IV spectrin-SD-IR AIS was greater than that for ankyrin-G-IR AIS for every participant (Figure 5).

\section{Effects of Possible Confounds}

The effects of possible confounds on the group differences in the densities of ankyrin-G-IR AIS in the superficial cortical zone are shown in Figure 6a. The mean difference from the matched normal comparison participant did not significantly differ when the subjects with schizophrenia were divided into groups based on sex $\left(F_{1,11}=0.025\right.$, $p=0.876)$, the use of antipsychotic $\left(\mathrm{F}_{1,10}=2.32\right.$, $p=0.159)$, benzodiazepine $\left(\mathrm{F}_{1,10}=0.11, p=0.746\right)$ or antidepressant $\left(\mathrm{F}_{1,10}=1.61, p=0.233\right)$ medications at the time of death, or a history of a substance use disorder $\left(\mathrm{F}_{1,10}=0.59, p=0.462\right)$. Interestingly, those subjects with schizophrenia on psychotropic medications at the time of death tended to have a smaller decrease in ankyrin-G-IR 
a

b

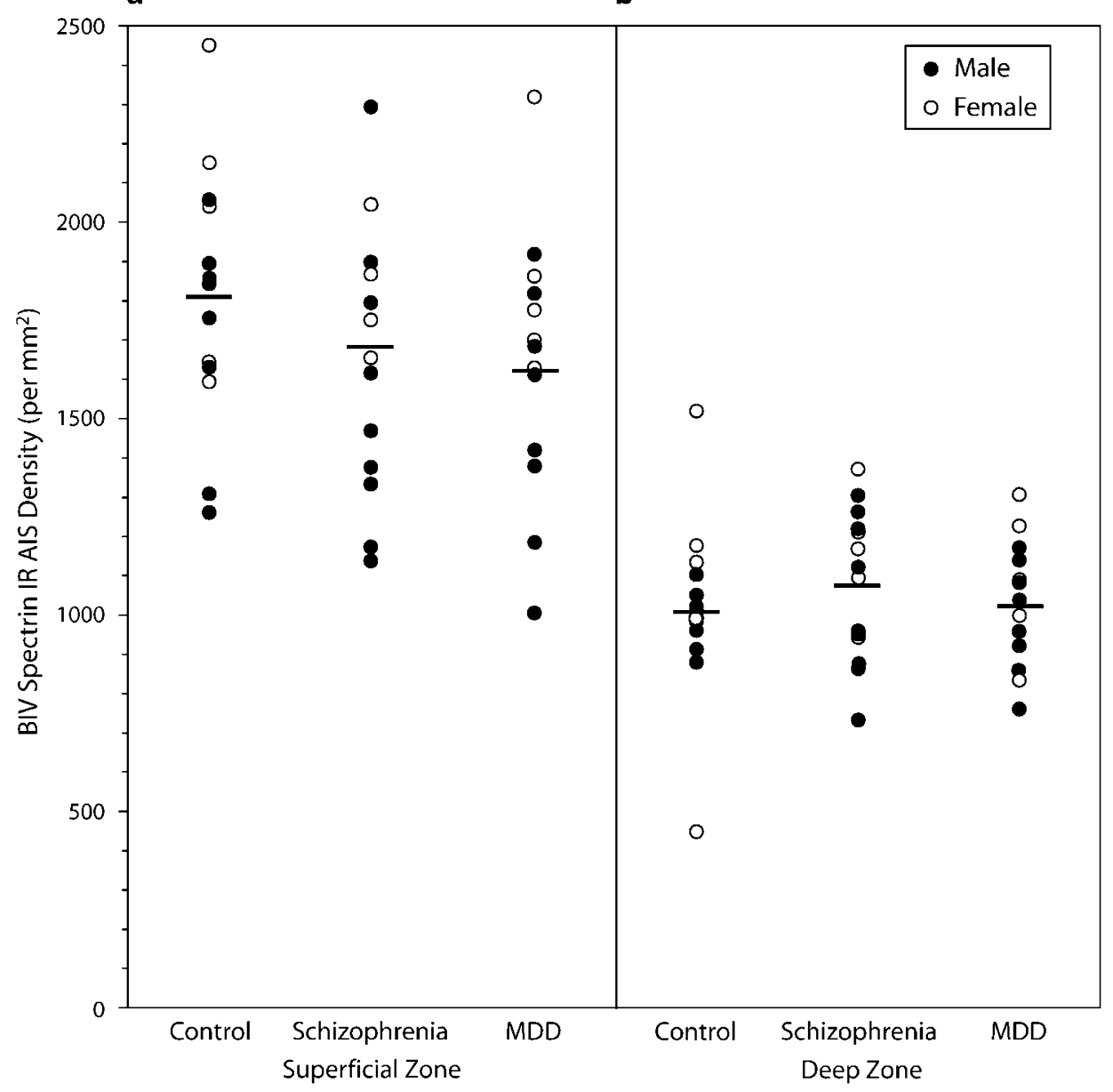

Figure 4 Scatter plots showing the mean densities of $\beta I V$ spectrin-SD immunoreactive AIS in each participant for each cortical zone. Horizontal lines indicate the mean density for each group. Note the generally higher density of $\beta I V$ spectrin-SD immunoreactive AIS for female participants in the superficial zone.

AIS density relative to their matched normal comparison participants (Figure 6a), suggesting that the use of medications might have obscured the magnitude of the decrease in ankyrin-G-IR AIS density due to the illness. The two subjects with schizophrenia who died by suicide had a much greater decrease in ankyrin-G-IR AIS density than those who died by other causes $\left(\mathrm{F}_{1,10}=5.73, p=0.038\right.$; Figure 6a). However, the subjects with schizophrenia with a cause of death other than suicide still showed a significant $\left(\mathrm{t}_{11}=2.38, p=0.036\right) 14 \%$ decrease in ankyrin-G-IR AIS density relative to their matched comparison participants. Finally, the density of ankyrin-G-IR AIS was similarly decreased $\left(\mathrm{F}_{1,10}=0.11, p=0.758\right)$ in both 'pure' schizophrenia $(n=11)$ and schizoaffective $(n=3)$ participants.

For the subjects with MDD (Figure 6b), the mean difference from their matched normal comparison cases in the density of ankyrin-G-IR AIS in the superficial zone did not significantly differ when MDD participants were divided on the basis of sex $\left(\mathrm{F}_{1,11}=1.53, p=0.243\right)$, the use of antipsychotic $\left(\mathrm{F}_{1,10}=0.05, p=0.829\right)$, benzodiazepine $\left(\mathrm{F}_{1,10}=2.75, p=0.128\right)$ or antidepressant $\left(\mathrm{F}_{1,10}=0.82\right.$, $p=0.388)$ medications at the time of death, history of substance use disorder $\left(\mathrm{F}_{1,10}=0.11, p=0.749\right)$, or manner of death $\left(\mathrm{F}_{1,10}=0.58, p=0.464\right)$. In addition, the mean difference from their matched normal comparison partici- pants did not differ between MDD participants with $(n=5)$ or without $(n=9)$ a history of psychosis $\left(\mathrm{F}_{1,10}=0.34\right.$, $p=0.575$ ), suggesting that the lower density of ankyrin-GIR AIS in the superficial zone of the subjects with schizophrenia reflects the disease process of schizophrenia and not a more general effect of psychosis.

The mean difference between matched pairs of schizophrenia and normal comparison participants in the density of $\beta$ IV spectrin-SD-IR AIS in the superficial zone did not significantly differ as a function of sex; antipsychotic, benzodiazepine, or antidepressant medication use at time of death; history of substance use disorder; or manner of death (all $F$ values $<1.15$; all $p$ values $>0.308$ ). Similarly, no differences between matched pairs of MDD and normal comparison participants in the density of $\beta \mathrm{IV}$ spectrin-SDIR AIS in the superficial zone were found as a function of any of these factors (all $F$ values $<1.64$; all $p$ values $>0.229$ ).

\section{Length of Ankyrin-G- and $\beta$ Iv Spectrin-SD-IR AIS}

As AIS length is associated with the probability that a given AIS will be contained, and identified, in a given tissue section, diagnosis-associated differences in the length of ankyrin-G- or $\beta$ IV spectrin-SD-IR AIS could potentially 


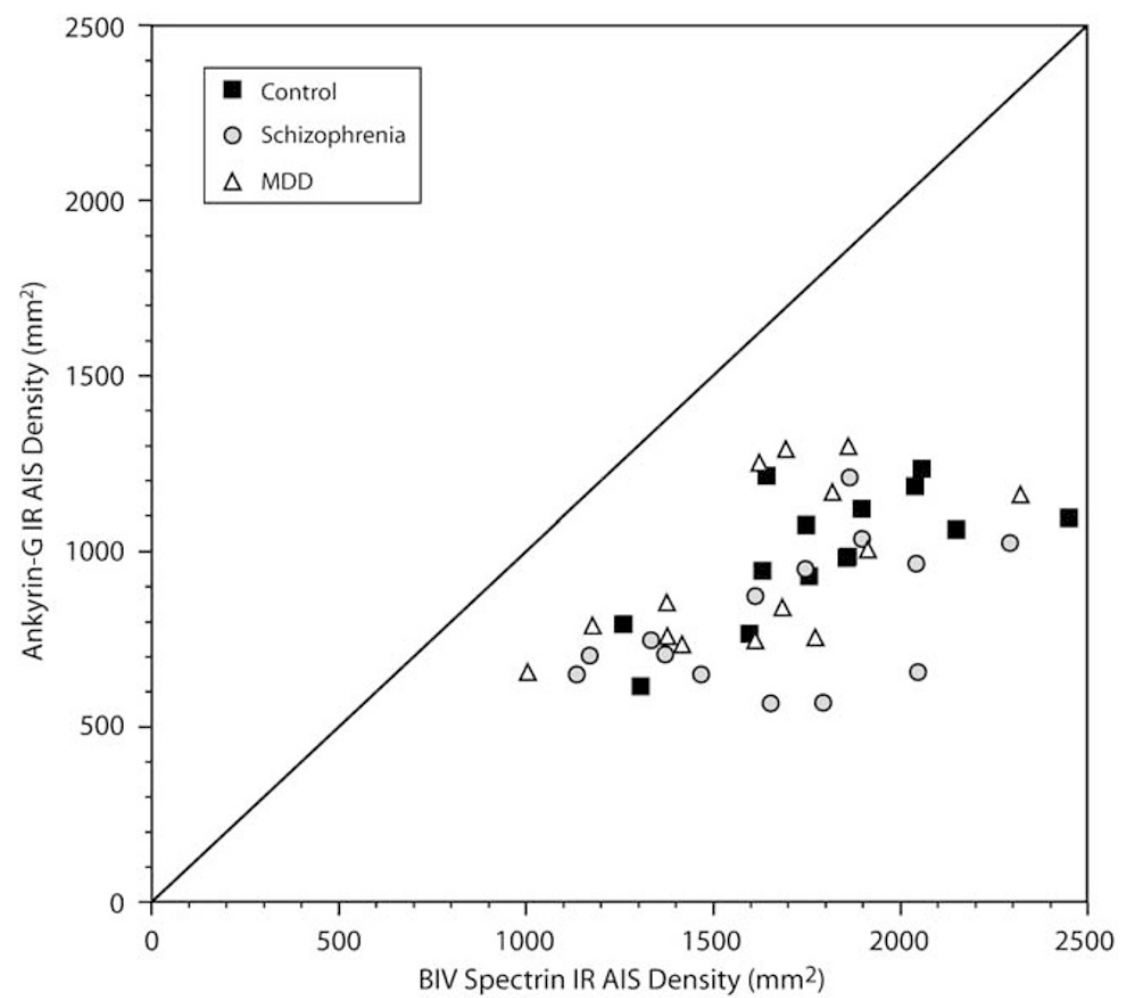

Figure 5 Scatter plot showing the relationship between ankyrin-G- and $\beta I V$ spectrin-SD-immunoreactive AIS density in the superficial cortical zone for each participant. All values fall below the unity line indicating a greater density of $\beta \mid \mathrm{V}$ spectrin-SD-immunoreactive AIS in every participant.

confound our density measures. However, mean AIS length in the superficial cortical zone did not differ between normal comparison and subjects with schizophrenia for either ankyrin- $\mathrm{G}\left(\mathrm{F}_{1,23}=2.31, p=0.14\right)$ or $\beta \mathrm{IV}$ spectrin-SD $\left(\mathrm{F}_{1,23}=1.42, p=0.25\right)$.

\section{Ankyrin-G-IR AIS in Antipsychotic Exposed Monkeys}

To further examine the potential effect of antipsychotic medications on ankyrin-G-IR AIS density, we determined the density of ankyrin-G-IR AIS in dIPFC area 46 of monkeys that had been exposed to haldoperidol, olanzapine, or placebo (Figure 7). As in humans, the density of labeled AIS was consistently greater in the superficial than in the deep cortical zone for each participant, but the mean density of ankyrin-G-IR AIS did not significantly differ across participant groups in either the superficial $\left(\mathrm{F}_{2,14}=0.29, p=0.75\right)$ or deep $\left(\mathrm{F}_{2,14}=0.49, p=0.62\right)$ zones.

\section{DISCUSSION}

In this study, the density of ankyrin-G-IR AIS in subjects with schizophrenia was significantly reduced in the superficial, but not in the deep, cortical layers compared with both normal comparison and subjects with MDD. This difference appears to reflect the underlying disease process of schizophrenia and not potential confounding factors. In contrast, the density of $\beta$ IV spectrin-SD-IR AIS did not significantly differ across diagnostic groups in either the superficial or deep cortical layers.

\section{Methodological Considerations}

We used the stereological principle of systematic random sampling to reduce sampling bias. However, due to the unavailability of the entire dlPFC for all participants, we report relative densities of labeled AIS instead of total numbers. This profile-counting approach is subject to two potential confounds. First, the detectability of labeled AIS is dependent on their length and how much of that length is present in tissue sections; the latter is determined by the angle of cut of the tissue relative to the long axis of AIS. These issues do not appear to have confounded our results as the length of labeled AIS did not differ between the schizophrenia and normal comparison participant groups, and only locations in area 46 that were cut perpendicular to the pial surface, and parallel to the long axis of AIS, were sampled. Second, the density of labeled AIS is dependent on both the number of AIS and cortical volume. However, systematic confounding due to differences in reference volume seems unlikely given that in these same participants (1) earlier measures of cortical thickness found no group differences (Pierri et al 1999), and (2) the densities of ankyrin-G-IR, $\beta \mathrm{IV}$ spectrin-SD-IR, and $\mathrm{GABA}_{\mathrm{A}}$ receptor $\alpha 2$ subunit-IR (Volk et al 2002) AISs were decreased, unchanged, and increased, respectively, in these participants with schizophrenia relative to comparison participants. Furthermore, if the volume of the dlPFC was reduced in the subjects with schizophrenia, as reported in some structural imaging studies (Shenton et al, 2001), then the lower density of ankyrin-G-IR AIS in schizophrenia observed in this study is likely to underestimate the true disease-related reduction 


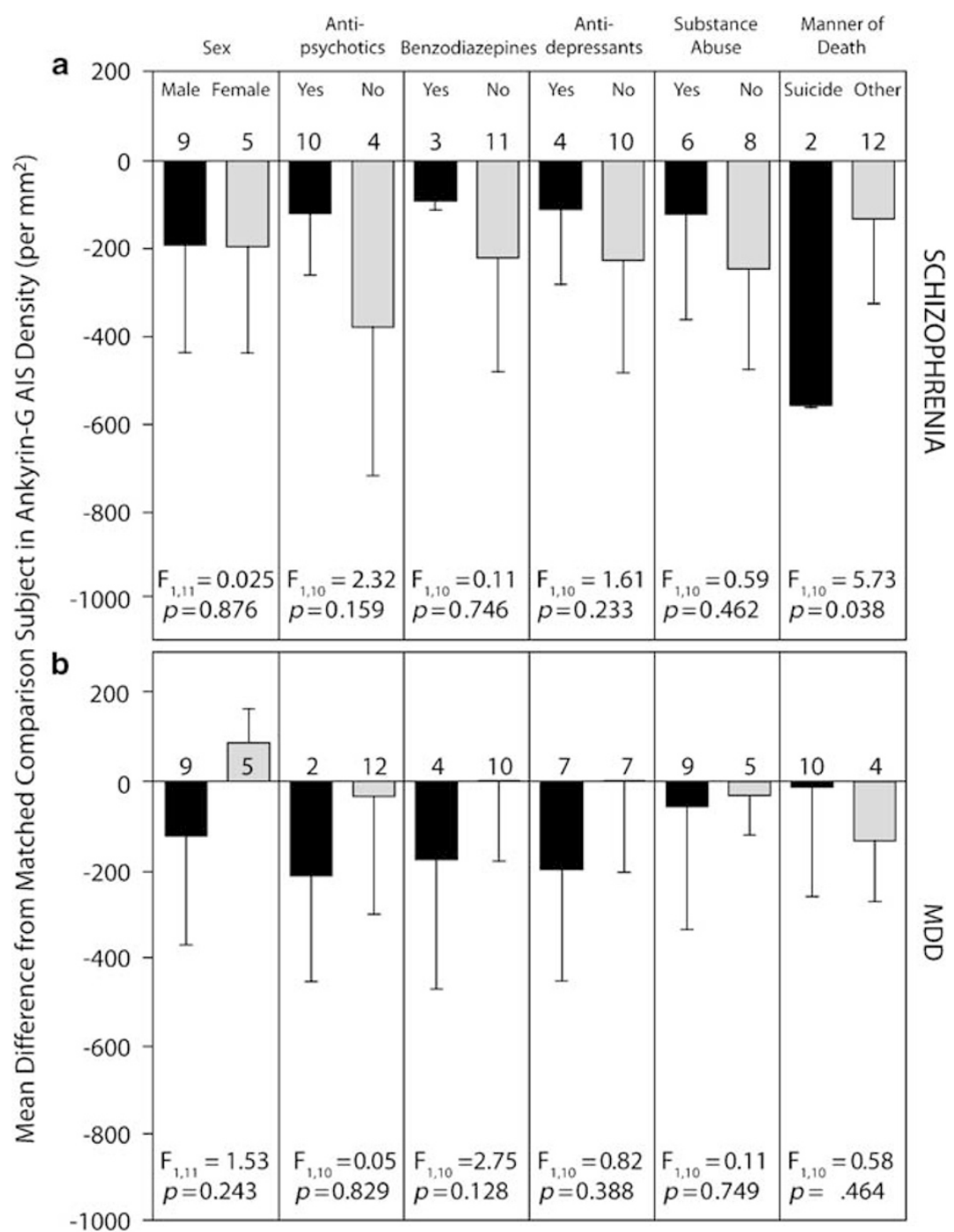

Figure 6 Bar graphs showing the mean ( \pm SD) difference from the matched normal comparison participant for ankyrin-G immunoreactive AIS density in the superficial zone for schizophrenia (panel a) and MDD (panel b) groups. Schizophrenia and MDD subjects are separated into groups according to sex; use of antipsychotics, benzodiazepines, or antidepressants at time of death; history of substance use disorder; and manner of death. The numbers at the origin line indicate the number of participants in each group.

in the number of AIS with detectable levels of ankyrin-G immunoreactivity.

The densities of both ankyrin-G- and $\beta$ IV spectrin-SD-IR AIS in the superficial layers differed as a function of sex, with females having greater densities in all participant groups (Figures 3a and 4a). Interestingly, earlier we did not find a difference in the densities of ankyrin-G- or $\beta \mathrm{IV}$ spectrin-SD-IR AIS between male and female monkeys, or as a function of menstrual status in a small group of female monkeys (Cruz et al, 2009). Thus, whether the sex difference observed in the present study is distinctive to humans, and if so, the basis for it, requires further study.

None of the other factors examined (Figure 6a) accounted for the lower density of ankyrin-G-IR AIS in the superficial zone of schizophrenia participants, and no effects of typical or atypical antipsychotic medications on ankyrin-G-IR AIS density were observed in monkeys (Figure 7). These findings, and the absence of a difference in ankyrin-G-IR
AIS density between MDD and normal comparison participants, or between MDD subjects with or without a history of psychosis, suggests that the lower density of ankyrin-G-IR AIS in the superficial zone of subjects with schizophrenia is specific to the disease process associated with this clinical diagnosis.

However, it is important to note that the gene that encodes ankyrin-G protein, ANK3, has recently been shown to be a susceptibility gene for bipolar disorder (Ferriera et al, 2008; Schulze et al, 2008). Given the evidence for shared genetic vulnerabilities between bipolar disorder and schizophrenia, it would be interesting to see if markers of GABA neurotransmission at the AIS of pyramidal neurons are altered in bipolar disorder. If genetic variants in the ANK3 gene also confer risk for schizophrenia, then these variants might contribute to reduced levels of ankyrin-G protein, but why such changes would be pronounced in a subset of pyramidal neurons is unclear. 


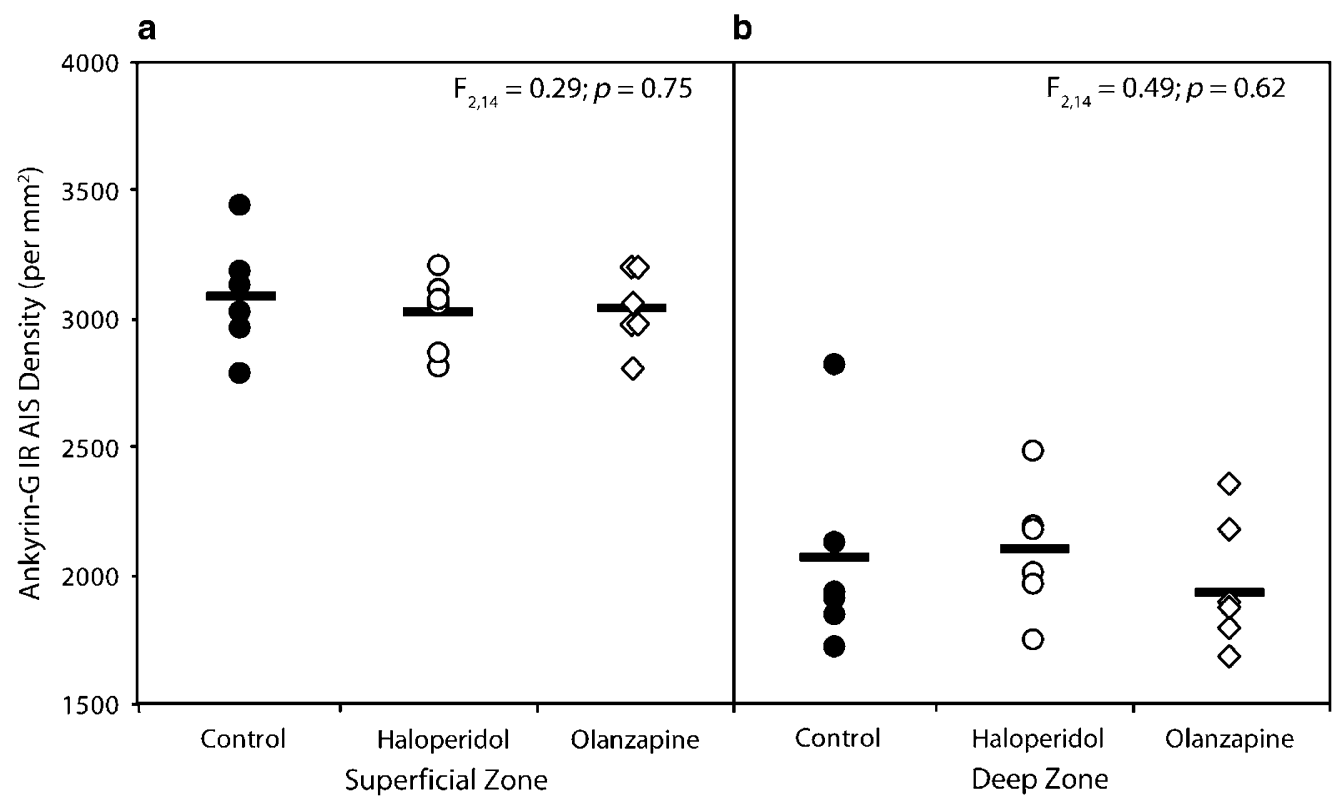

Figure 7 Scatter plots showing the mean densities of ankyrin-G-IR AIS in each participant for each cortical zone in placebo-, haloperidol-, and olanzapineexposed monkeys. Horizontal lines indicate the mean density for each group.

\section{Functional Significance}

The laminar specificity of the ankyrin-G-IR AIS findings are consistent with earlier observations that pyramidal cell alterations in schizophrenia are more marked in the superficial cortical layers. For example, alterations in both pre-synaptic (ie lower density of GAT1-IR chandelier cell axon cartridges; Pierri et al, 1999) and post-synaptic (ie higher density of AIS IR for the GABA $\mathrm{A}_{\mathrm{A}}$ receptor $\alpha 2$ subunit; Volk et al, 2002) markers of GABA inputs to pyramidal cell AISs are more prominent in the superficial than the deep layers of the dlPFC in schizophrenia. Similarly, smaller somal volume and lower spine density of pyramidal neurons in schizophrenia are also preferentially found on layer 3 relative to layers 5-6 pyramidal neurons in both the dlPFC (Pierri et al, 2001; Glantz and Lewis, 2000; Kolluri et al, 2005; Rajkowska et al, 1998) and auditory cortex (Sweet et al, 2003; Sweet et al, 2004; Sweet et al, 2008). As the majority of pyramidal neurons in dlPFC layers 2-3 project to other cortical areas (Jones, 1984), these laminaspecific alterations suggest a greater impact on corticalcortical than on cortical-subcortical information processing in subjects with schizophrenia. Interestingly, in the superficial layers, the densities of AIS IR for ankyrin-G and for the $\mathrm{GABA}_{\mathrm{A}}$ receptor $\alpha 2$ subunit (Volk et al, 2002) were significantly inversely correlated in the schizophrenia subjects $(r=-0.690, p=0.006)$ but not in the control subjects $(r=-0.229, p=0.430)$. These findings suggest that a common factor may contribute to the changes in both ankyrin- $G$ and the $\mathrm{GABA}_{\mathrm{A}}$ receptor $\alpha 2$ subunits at AIS in DLPFC layers 2-3 in subjects with schizophrenia. For example, if GABAergic innervation is required for the localization of ankyrin-G and the formation of the AIS (Hedstrom et al, 2008; Ango et al, 2004), then lower GABA neurotransmission from chandelier cells (due to a deficit in expression of the GABA synthesizing enzyme, GAD67 (Lewis et al, 2005)) to pyramidal cell AIS would be reflected in both decreased ankyrin- $G$ and a compensatory increase in GABA receptors containing the $\alpha 2$ subunit. Similarly, the lower densities of both ankyrin-G- and $\beta$ IV spectrin-SD-IR AIS in the deep relative to the superficial cortical zones might reflect the lower number of chandelier cell synapses on the AIS of pyramidal neurons in layer 6 relative to layer 3 (Farinas and DeFelipe, 1991). Fewer synaptic inputs might be associated with lower levels of immunoreactivity per AIS, creating the possibility that some AIS in the deep zone were not detected, and thus that diagnosis-related differences were missed.

The lower density of ankyrin-G-IR AIS in the superficial layers likely represents a reduced amount of ankyrin-G protein in a subset of AIS, rather than fewer AIS, for the following reasons. First, the density of $\beta$ IV spectrin-SD-IR AIS was unchanged in schizophrenia, and exceeded the density of ankyrin-G-IR AIS in every participant, including normal comparison subjects, indicating that AISs are still present in schizophrenia. The consistent difference in the densities of ankyrin-G-IR and $\beta$ IV spectrin-SD-IR AIS might merely reflect a greater sensitivity of $\beta$ IV spectrin-SD antibody. Thus, our findings suggest that in schizophrenia, a subset of pyramidal neuron AISs have reduced levels of ankyrin-G protein such that they are no longer detectable by immunocytochemistry, whereas the levels of $\beta \mathrm{IV}$ spectrin in these AIS is still sufficient to be detected. Second, both the total number of prefrontal neurons (Thune et al, 2001), and the tissue shrinkage-corrected density of layer 3 pyramidal neurons (Maldonado-Aviles et al, 2006), are unchanged in subjects with schizophrenia, indicating that the source neurons of AISs are still present.

Although both ankyrin-G and $\beta$ IV spectrin play roles in the formation and maintenance of the membrane protein complexes that comprise the AIS, ankyrin-G appears to be the principal organizer of the AIS. For example, in ankyrin$\mathrm{G}$ knock-out mice, $\beta \mathrm{IV}$ spectrin, as well as sodium and potassium ion channels, fail to cluster at the AIS of Purkinje neurons (Zhou et al, 1998; Bennett and Baines, 2001; Pan 
et al, 2006). In contrast, ankyrin-G is properly localized to the AIS in $\beta \mathrm{IV}$ spectrin knock-out mice (Yang et al, 2004) and $\beta \mathrm{IV}$ spectrin by itself cannot recruit proteins, such as sodium channels, to the AIS (Yang et al, 2007). Thus, the lower levels of ankyrin-G protein in schizophrenia may translate into a deficit in the levels of sodium channels localized to the AIS, and consequently to a reduced capacity of layers 2-3 pyramidal neurons to generate action potentials. Ankyrin-G also localizes and retains the cell adhesion molecule, neurofascin 186, to the AIS of projection neurons (Ango et al, 2004; Boiko et al, 2007). Through its interaction with ankyrin-G, neurofascin 186 is responsible for the recruitment of GABA synapses to the AIS of cerebellar purkinje neurons (Ango et al, 2004). If this same mechanism is operative in cortical pyramidal neurons, then lower levels of ankyrin-G could lead to a smaller number of GABA synapses at the AIS of layers 2-3 pyramidal neurons in schizophrenia. These hypotheses may be tested in future studies by examining immunoreactivity for voltage-gated sodium channels and neurofascin 186 in the AIS of subjects with schizophrenia.

The combination of lower synaptic input from chandelier neurons and impaired action potential generation could disrupt the capacity of pyramidal neurons to fire in the repetitive and synchronous fashion required for cortical network oscillations, such as those in the gamma band (30$80 \mathrm{~Hz}$ ) range (Gonzalez-Burgos and Lewis, 2008). Prefrontal gamma oscillations are associated with certain cognitive processes, such as working memory, that are disturbed in schizophrenia, and cognitive task-induced gamma oscillations in the frontal lobes are reduced in schizophrenia (Cho et al, 2006). Although additional studies are required to determine the cause-effect relationships between alterations at the site of chandelier-pyramidal neuron synapses, the findings of this study further define the molecular nature of those alterations and may suggest novel targets for therapeutic interventions to improve cognition in schizophrenia.

\section{ACKNOWLEDGEMENTS}

Supported by NIH grants MH043784, MH045156, and MH084053 from the National Institute of Mental Health. The content is solely the responsibility of the authors and does not necessarily represent the official views of the National Institute of Mental Health or the National Institutes of Health. The authors thank Dr Matthew Rasband for providing the $\beta \mathrm{IV}$ spectrin antibody, Mary Brady for excellent assistance with the figures, Lindsay Karr for preparing the manuscript, and the members of the Clinical Services and Diagnostics Core of the Conte Center for the Neuroscience of Mental Disorders (MH084053) for their assistance in diagnostic assessments.

\section{DISCLOSURE/CONFLICT OF INTEREST}

David A. Lewis currently receives investigator-initiated research support from the BMS Foundation, Bristol-Myers Squibb, Curridium Ltd and Pfizer and in 2007-2009 served as a consultant in the areas of target identification and validation and new compound development to AstraZeneca,
Bristol-Myers Squibb, Hoffman-Roche, Lilly, Merck, and Neurogen. All other authors have no conflicts of interest to disclose.

\section{REFERENCES}

Akbarian S, Huntsman MS, Kim JJ, Tafazzoli A, Potkin SG, Bunney Jr WE et al. (1995). GABA $\mathrm{A}_{\mathrm{A}}$ receptor subunit gene expression in human prefrontal cortex: comparison of schizophrenics and controls. Cereb Cortex 5: 550-560.

Ango F, Di Cristo G, Higashiyama H, Bennett V, Wu P, Huang ZJ (2004). Ankyrin-based subcellular gradient of neurofascin, an immunoglobulin family protein, directs GABAergic innervation at purkinje axon initial segment. Cell 119: 257-272.

Bennett V, Baines AJ (2001). Spectrin and ankyrin-based pathways: metazoan inventions for integrating cells into tissues. Physiol Rev 81: 1353-1392.

Boiko T, Vakulenko M, Ewers H, Yap CC, Norden C, Winckler B (2007). Ankyrin-dependent and -independent mechanisms orchestrate axonal compartmentalization of L1 family members neurofascin and L1/neuron-glia cell adhesion molecule. J Neurosci 27: 590-603.

Cho RY, Konecky RO, Carter CS (2006). Impairments in frontal cortical gamma synchrony and cognitive control in schizophrenia. Proc Natl Acad Sci USA 103: 19878-19883.

Cruz DA, Eggan SM, Lewis DA (2003). Postnatal development of pre- and post-synaptic GABA markers at chandelier cell inputs to pyramidal neurons in monkey prefrontal cortex. J Comp Neurol 465: 385-400.

Cruz DA, Lovallo EM, Stockton S, Rasband M, Lewis DA (2009). Postnatal development of synaptic structure proteins in pyramidal neuron axon initial segments in monkey prefrontal cortex. J Comp Neurol (in press).

Daviss SR, Lewis DA (1995). Local circuit neurons of the prefrontal cortex in schizophrenia: selective increase in the density of calbindin-immunoreactive neurons. Psychiatry Res 59: 81-96.

Dorph-Petersen K-A, Pierri JN, Perel JM, Sun Z, Sampson AR, Lewis DA (2005). The influence of chronic exposure to antipsychotic medications on brain size before and after tissue fixation: a comparison of haloperidol and olanzapine in macaque monkeys. Neuropsychopharmacology 30: 1649-1661.

Erickson SL, Akil M, Levey AI, Lewis DA (1998). Postnatal development of tyrosine hydroxylase- and dopamine transporter-immunoreactive axons in monkey rostral entorhinal cortex. Cereb Cortex 8: 415-427.

Farinas I, DeFelipe J (1991). Patterns of synaptic input on corticocortical and corticothalamic cells in the cat visual cortex. II. The axon initial segment. J Comp Neurol 304: 70-77.

Ferreira MA, O’Donovan MC, Meng YA, Jones IR, Ruderfer DM, Jones L et al (2008). Collaborative genome-wide association analysis supports a role for ANK3 and CACNA1C in bipolar disorder. Nat Genet 40: 1056-1058.

Glantz LA, Lewis DA (1997). Reduction of synaptophysin immunoreactivity in the prefrontal cortex of subjects with schizophrenia: regional and diagnostic specificity. Arch Gen Psychiatry 54: 943-952.

Glantz LA, Lewis DA (2000). Decreased dendritic spine density on prefrontal cortical pyramidal neurons in schizophrenia. Arch Gen Psychiatry 57: 65-73.

Gonzalez-Burgos G, Lewis DA (2008). GABA neurons and the mechanisms of network oscillations: implications for understanding cortical dysfunction in schizophrenia. Schizophr Bull 34: 944-961.

Guidotti A, Auta J, Davis JM, Gerevini VD, Dwivedi Y, Grayson DR et al (2000). Decrease in reelin and glutamic acid decarboxylase $_{67}\left(\mathrm{GAD}_{67}\right)$ expression in schizophrenia and bipolar disorder. Arch Gen Psychiatry 57: 1061-1069. 
Hashimoto T, Arion D, Unger T, Maldonado-Aviles JG, Morris HM, Volk DW et al. (2008). Alterations in GABA-related transcriptome in the dorsolateral prefrontal cortex of subjects with schizophrenia. Mol Psychiatry 13: 147-161.

Hashimoto T, Volk DW, Eggan SM, Mirnics K, Pierri JN, Sun Z et al. (2003). Gene expression deficits in a subclass of GABA neurons in the prefrontal cortex of subjects with schizophrenia. J Neurosci 23: 6315-6326.

Hedstrom KL, Ogawa Y, Rasband MN (2008). Ankyring is required for maintenance of the axon initial segment and neuronal polarity. J Cell Biol 183: 635-640.

Jenkins SM, Bennett V (2001). Ankyrin-G coordinates assembly of the spectrin-based membrane skeleton, voltage-gated sodium channels, and L1 CAMs at Purkinje neuron initial segments. J Cell Biol 155: 739-745.

Jenkins SM, Bennett V (2002). Developing nodes of Ranvier are defined by ankyrin-G clustering and are independent of paranodal axoglial adhesion. Proc Natl Acad Sci USA 99: 2303-2308.

Jenkins SM, Kizhatil K, Kramarcy NR, Sen A, Sealock R, Bennett V (2001). FIGQY phosphorylation defines discrete populations of L1 cell adhesion molecules at sites of cell-cell contact and in migrating neurons. J Cell Sci 114: 3823-3835.

Jiao Y, Sun Z, Lee T, Fusco FR, Kimble TD, Meade CA et al. (1999). A simple and sensitive antigen retrieval method for free-floating and slide-mounted tissue sections. J Neurosci Meth 93: $149-162$.

Jones EG (1984). Laminar distribution of cortical efferent cells. In: Peters A, Jones EG (eds). Cerebral Cortex, Vol. 1. Plenum Press: New York. pp 521-553.

Kolluri N, Sun Z, Sampson AR, Lewis DA (2005). Lamina-specific reductions in dendritic spine density in the prefrontal cortex of subjects with schizophrenia. Am J Psychiatry 162: 1200-1202.

Kordeli E, Lambert S, Bennett V (1995). AnkyrinG. A new ankyrin gene with neural-specific isoforms localized at the axonal initial segment and node of Ranvier. J Biol Chem 270: 2352-2359.

Lacas-Gervais S, Guo J, Strenzke N, Scarfone E, Kolpe M, Jahkel M et al. (2004). BetaIVSigmal spectrin stabilizes the nodes of Ranvier and axon initial segments. J Cell Biol 166: 983-990.

Lewis DA, Campbell MJ, Foote SL, Morrison JH (1986). The monoaminergic innervation of primate neocortex. Human Neurobiol 5: 181-188.

Lewis DA, Hashimoto T, Volk DW (2005). Cortical inhibitory neurons and schizophrenia. Nat Rev Neurosci 6: 312-324.

Maldonado-Aviles JG, Wu Q, Sampson AR, Lewis DA (2006). Somal size of immunolabeled pyramidal cells in the prefrontal cortex of subjects with schizophrenia. Biol Psychiatry 60: 226-234.

Melchitzky DS, Sesack SR, Lewis DA (1999). Parvalbuminimmunoreactive axon terminals in macaque monkey and human prefrontal cortex: laminar, regional and target specificity of type I and type II synapses. J Comp Neurol 408: 11-22.

Ohnuma T, Augood SJ, Arai H, McKenna PJ, Emson PC (1999). Measurement of GABAergic parameters in the prefrontal cortex in schizophrenia: focus on GABA content, GABA $\mathrm{A}_{\mathrm{A}}$ receptor $\alpha-1$ subunit messenger RNA and human GABA transporter-1 (HGAT-1) messenger RNA expression. Neuroscience 93: 441-448.

Pan ZM, Kao TC, Horvath Z, Lemos J, Sul JY, Cranstoun SD et al. (2006). A common ankyrin-G-based mechanism retains KCNQ and Na-V channels at electrically active domains of the axon. J Neurosci 26: 2599-2613.

Pierri JN, Chaudry AS, Woo T-U, Lewis DA (1999). Alterations in chandelier neuron axon terminals in the prefrontal cortex of schizophrenic subjects. Am J Psychiatry 156: 1709-1719.

Pierri JN, Volk CLE, Auh S, Sampson A, Lewis DA (2001). Decreased somal size of deep layer 3 pyramidal neurons in the prefrontal cortex of subjects with schizophrenia. Arch Gen Psychiatry 58: 466-473.

Pucak ML, Levitt JB, Lund JS, Lewis DA (1996). Patterns of intrinsic and associational circuitry in monkey prefrontal cortex. J Comp Neurol 376: 614-630.

Rajkowska G, Goldman-Rakic PS (1995). Cytoarchitectonic definition of prefrontal areas in the normal human cortex: I. Remapping of areas 9 and 46 using quantitative criteria. Cereb Cortex 5: 307-322.

Rajkowska G, Selemon LD, Goldman-Rakic PS (1998). Neuronal and glial somal size in the prefrontal cortex: a postmortem morphometric study of schizophrenia and Huntington disease. Arch Gen Psychiatry 55: 215-224.

Schulze TG, Detera-Wadleigh SD, Akula N, Gupta A, Kassem L, Steele J et al (2008). Two variants in Ankyrin 3 (ANK3) are independent genetic risk factors for bipolar disorder. $\mathrm{Mol}$ Psychiatry E-pub ahead of print 2008 Dec 16.

Shenton ME, Dickey CC, Frumin M, McCarley RW (2001). A review of MRI findings in schizophrenia. Schizophr Res 49: 1-52.

Susuki K, Rasband MN (2008). Spectrin and ankyrin-based cytoskeletons at polarized domains in myelinated axons. Exp Biol Med (Maywood) 233: 394-400.

Sweet RA, Bergen SE, Sun Z, Sampson AR, Pierri JN, Lewis DA (2004). Pyramidal cell size reduction in schizophrenia: evidence for involvement of auditory feedforward circuits. Biol Psychiatry 55: 1128-1137.

Sweet RA, Henteleff RA, Zhang W, Sampson AR, Lewis DA (2008). Reduced dendritic spine density in auditory cortex of subjects with schizophrenia. Neuropsychopharmacology Epub May 7, 2008.

Sweet RA, Pierri JN, Auh S, Sampson AR, Lewis DA (2003). Reduced pyramidal cell somal volume in auditory association cortex of subjects with schizophrenia. Neuropsychopharmacology 28: 599-609.

Thune JJ, Uylings HBM, Pakkenberg B (2001). No deficit in total number of neurons in the prefrontal cortex in schizophrenics. $J$ Psychiatr Res 35: 15-21.

Volk DW, Austin MC, Pierri JN, Sampson AR, Lewis DA (2000). Decreased glutamic acid decarboxylase67 messenger RNA expression in a subset of prefrontal cortical gamma-aminobutyric acid neurons in subjects with schizophrenia. Arch Gen Psychiatry 57: 237-245.

Volk DW, Austin MC, Pierri JN, Sampson AR, Lewis DA (2001). GABA transporter-1 mRNA in the prefrontal cortex in schizophrenia: decreased expression in a subset of neurons. Am J Psychiatry 158: 256-265.

Volk DW, Pierri JN, Fritschy J-M, Auh S, Sampson AR, Lewis DA (2002). Reciprocal alterations in pre- and postsynaptic inhibitory markers at chandelier cell inputs to pyramidal neurons in schizophrenia. Cereb Cortex 12: 1063-1070.

Williams SM, Goldman-Rakic PS, Leranth C (1992). The synaptology of parvalbumin-immunoreactive neurons in primate prefrontal cortex. J Comp Neurol 320: 353-369.

Woo T-U, Whitehead RE, Melchitzky DS, Lewis DA (1998). A subclass of prefrontal gamma-aminobutyric acid axon terminals are selectively altered in schizophrenia. Proc Natl Acad Sci USA 95: 5341-5346.

Yang Y, Lacas-Gervais S, Morest DK, Solimena M, Rasband MN (2004). BetaIV spectrins are essential for membrane stability and the molecular organization of nodes of Ranvier. J Neurosci 24 7230-7240.

Yang Y, Ogawa Y, Hedstrom KL, Rasband MN (2007). beta IV spectrin is recruited to axon initial segments and nodes of Ranvier by ankyrinG. J Cell Biol 176: 509-519.

Zhou DX, Lambert S, Malen PL, Carpenter S, Boland LM, Bennett $\mathrm{V}$ (1998). Ankyrin(G) is required for clustering of voltage-gated $\mathrm{Na}$ channels at axon initial segments and for normal action potential firing. J Cell Biol 143: 1295-1304. 